\title{
DIVERSIDADE CULTURAL - DIÁLOGOS INTERDISCIPLINARES ENTRE POVOS INDÍGENAS E NÃO INDÍGENAS - UMA EXPERIENCIA NA FORMAÇÃO INICIAL DOCENTE
}

\section{CULTURAL DIVERSITY - DIALOGUE BETWEEN INTERDISCIPLINARY INDIGENOUS PEOPLES AND NON INDIGENOUS - AN EXPERIMENT IN INITIAL TEACHER TRAINING}

\author{
Letícia Ramos Silva ${ }^{1}$ \\ Sônia Maria Pereira Lima² \\ Norma Abreu e Lima Maciel Vasconcelos ${ }^{3}$
}

\section{RESUMO}

Este texto apresenta uma discussão sobre diálogos interdisciplinares a partir do resultado de uma pesquisa qualitativa que trata da diversidade cultural no currículo da Educação Básica e do Ensino Superior. Esta pesquisa estabeleceu um diálogo entre as disciplinas Educação e Multiculturalismo, Ética e Cidadania no Curso de Licenciatura Plena em Pedagogia oferecido pelo Plano Nacional de Formação de Professores da Educação Básica - PARFOR, no campus da Universidade de Pernambuco. Com o olhar voltado para a formação inicial de Professores na perspectiva de Ensino, Pesquisa e Extensão, objetivamos oportunizar o professor da Educação Básica e estudante do referido curso, a refletir sobre a importância de se inserir estudos acerca da diversidade cultural desde os anos iniciais do Ensino Fundamental através de projetos interdisciplinares que envolvam a troca de experiências entre povos indígenas e não indígenas . A amostra do estudo contou com estudantes do $3^{\circ}$ período de Pedagogia da Universidade de Pernambuco e com coordenadores, professores e lideranças das escolas indígenas Fulni-ô localizadas no município de Águas Belas. Conclui-se apontando a necessidade de que sejam elaborados projetos de extensão que priorizem à valorização da cultura indígena $\mathrm{e}$ do respeito a diversidade cultural e a interculturalidade no currículo da formação inicial de professores, como meio de qualificação profissional e de reflexos positivos no fazer docente da Educação Básica a partir de um olhar direcionado para a inclusão social. Acrescenta-se ainda a importância de que essa temática seja pauta de discussão e estudo na formação continuada de professores da Educação Básica, por ser esta considerada um instrumento de atualização e melhoria da ação docente no processo de ensino e aprendizagem, sobretudo na escola pública.

Palavras-chave: Formação Docente. Diversidade Cultural. Interdisciplinaridade e Ética.

\footnotetext{
${ }^{1}$ Mestre em Ciência Política (UFPE). Professora pela Universidade de Pernambuco.

E-mail: ticiaramos3@yahoo.com.br.

${ }^{2}$ Mestranda em Educação (UFRN). Técnica de Ensino da Secretaria de Educação do

Estado de Pernambuco. E-mail: sonia.lima2013@yahoo.com.br.

${ }^{3}$ Doutoranda em Educação (UFSCar). E-mail: normamvasconcelos@ yahoo.com.br.

Revista Ambivalências

V.4 $\bullet$ N.7 $\bullet$ p. $309-323 \cdot$ Jan-Jun/2016

ISSN 2318-3888 • DOI: 10.21665/2318-3888.v4n7p309-323
} 


\begin{abstract}
This paper presents a discussion of interdisciplinary dialogues from the results of a qualitative research that deals with cultural diversity in the curriculum of Basic Education and Higher Education. This research established a dialogue between the Education and Multiculturalism disciplines, Ethics and Citizenship in Full Degree in Education offered by the Education National Teacher Training Plan Basic - PARFOR on the campus of the University of Pernambuco. With eyes on the initial training of teachers in education perspective and Research, aimed to provide the opportunity for teachers of Basic Education and student that course, to reflect on the importance of entering studies of cultural diversity since the early years of Elementary education through interdisciplinary projects involving the exchange of experiences between indigenous and non-indigenous. The study sample included students of the 3rd period Pedagogy of the University of Pernambuco and coordinators, teachers and leaders of Fulni-ô indigenous schools located in the city of Águas Belas. We conclude pointing out the need to be prepared extension projects that give priority to the appreciation of indigenous culture and respect cultural diversity and interculturalism in the curriculum of initial teacher education as a means of professional qualifications and positive impact on making teaching of Basic education from a gaze directed to social inclusion. It is further the importance of this issue is the agenda of discussion and study in the continuing education of teachers of basic education, as this is considered a tool to update and improve the teaching action in the process of teaching and learning, especially in public schools.
\end{abstract}

Keywords: Teacher Training. Cultural Diversity. Interdisciplinarity and Ethics. 


\section{Introdução}

Este texto discute a importância do diálogo interdisciplinar no Curso de Licenciatura em Pedagogia oferecido no Campus da Universidade de Pernambuco, localizada no interior do Estado de Pernambuco, através do Plano Nacional de Formação de Professores da Educação Básica-PARFOR. Por esse viés, voltamos o olhar para a formação inicial de professores na perspectiva de Ensino, Pesquisa e Extensão, partindo da reflexão sobre a própria prática e da inserção de princípios de contextualização e interdisciplinaridade no cotidiano das disciplinas propostas pela Matriz Curricular do Curso.

A inclusão dos estudantes do PARFOR, sendo estes professores oriundos da Rede Municipal, vislumbra uma nova perspectiva de fazer pedagógico no contexto da Educação Básica, uma vez que essa iniciativa transcende os muros da continuidade de práticas convencionais que, anos a fio, insistem em se estabelecer no cotidiano das aulas, sobretudo na escola pública.

Diante dessa situação de ensino e pesquisa, observa-se que a qualificação profissional, discutida em termos de melhoria do fazer docente no campo da Educação Básica, coloca a formação inicial de professores como prioridade na luta por uma melhoria no desempenho escolar da Educação Básica. Nesse sentido, Nóvoa ressalta que,

O trabalho dos professores precisa ser imaginado a partir, de uma nova formação, das práticas e do associativismo e de um novo entendimento das políticas educacionais, entendida não como um conjunto de micro competências adicionadas, mas como uma realidade que privilegia a todo um sistema, onde se valorizam conhecimentos, capacidades, atitudes, níveis de adequação de intenções, todos expressos num conjunto de relações interpessoais e institucionais que determinam o exercício adequado da profissão (NÓVOA, 1995, p. 52).

Nesse sentido, os cursos de formação inicial de professores assumem um papel muito importante para a melhoria do rendimento escolar na educação básica, uma vez que em sua maioria, os estudantes dos cursos de Licenciatura e/ou Normal Médio são professores da Educação Básica. Ainda com relação à Educação Básica, temos presenciado diversos tipos de iniciativa, que têm colocado a 
atualização teórica e prática dos professores como meio de inclusão de mudanças significativas na prática docente, sobretudo nas escolas que oferecem os anos iniciais do Ensino Fundamental. E, nesse sentido, um dos caminhos considerados viáveis para a efetivação dessas prioridades no cenário educacional são os cursos de formação inicial e continuada de professores nas universidades, uma vez que estes têm como principal finalidade a formação e profissionalização docente. Sob essa perspectiva, o maior desafio das universidades tem sido, criar alternativas pedagógicas que oportunizem esses professores a adquirir conhecimentos teóricos e práticos, que contemplem, não somente o estudo de conteúdos específicos definidos no ementário de cada disciplina do curso, mas também uma atualização didática compatível com a realidade de ensino e de aprendizagem presente no cotidiano dessas escolas públicas.

As Universidades, assumindo uma formação inicial de professores com essa perspectiva de ensino, valoriza a experiência docente dos estudantes que procuram as universidades em busca de múltiplos saberes, e, sobretudo, rompe com o paradigma de distanciamento que há anos existe na relação entre formação docente (científica) e a realidade da educação básica presente no seio das escolas públicas e que recebem como docentes professores que saem desses cursos de formação.

Na perspectiva de rever essa realidade educacional e contribuir para a efetivação dessas mudanças no campo de formação inicial e continuada de professores, resolvemos enquanto pesquisadoras iniciar uma discussão sobre o assunto, a partir de uma proposta de diálogo interdisciplinar em interface com a pesquisa de iniciação científica no curso de formação inicial de professores ( $1^{\mathrm{a}}$ licenciatura).

A partir dos resultados de um diagnóstico realizado com estudantes egressos do ensino médio de escola pública inscritos no curso de Pedagogia oferecido pelo Plano Nacional de Formação de Professores na Plataforma Freire no Campus da Universidade de Pernambuco em Garanhuns - Pernambuco, percebemos que uma das maiores dificuldades apresentadas por esses estudantes refere-se a prática de produção de textos, bem como de se expressar em público para socializar um conhecimento apreendido ou construído. 
Assim, partindo dessa constatação e, entendendo que há necessidade nos dias atuais, de que a escola enquanto instituição social a serviço da cidadania ensine valores que contribuam para o respeito aos direitos humanos, a partir da vivência de um currículo articulado aos múltiplos saberes e a diversidade cultural, remetemos o olhar para as Universidades na tentativa de que os Cursos de Formação Inicial de Professores sirvam de instrumentos de mudanças qualitativas na e para a ação docente, superando a fragmentação de um ensino técnicolinear, que pode-se dizer, apresenta em muitos Cursos de Formação Inicial de Professores: a preocupação apenas com o resultado e a quantidade de aprovações geradas com o estudo de conteúdos contemplados em disciplinas específicas do referido curso.

Por outro lado, na concepção de currículo que viabiliza a relação dialética de ensino e aprendizagem como princípio educativo, inclui a constituição de saberes numa relação interativa entre professor, estudante e conhecimentos no processo de formação significativa de aprendizagem, pois "desenvolve a capacidade de comunicar ideias e, reforço, de pensar melhor não apenas as práticas, mas também conceitos e proposições levadas à sala de aula é, do mesmo modo, ponto decisivo para que a educação melhore.

À luz dessa perspectiva chegamos ao núcleo de nossa discussão, tomando como referência uma questão norteadora: de que forma o ensino na perspectiva de diálogo interdisciplinar apresenta contribuições significativas para a inserção de um novo fazer docente desde os cursos de Formação de Professores da Educação Básica? Para responder a essa questão, tomamos como referência Nóvoa ao afirmar,

que é necessário repensar os modos de organização do trabalho escolar, desde as estruturas físicas das escolas até a estrutura curricular das disciplinas e dos programas; desde as formas de agrupamento e de acompanhamento dos alunos até as modalidades de recrutamento e de contratação dos professores. Temos de reinventar a escola se queremos que ela cumpra um papel relevante nas sociedades do século XX4 (NÓVOA, 1995, p.29).

Nesse contexto, a metodologia do professor deve aliar o amor à competência profissional e, sobretudo, a um comportamento político claro, a fim de que os Cursos de Formação Inicial de Professores sejam 
espaços de construção de conhecimentos e de leituras de realidades à luz da dimensão de currículo que articula teoria e prática de forma dinâmica, reflexiva, crítica e contextualizada.

Embasadas nessa teoria, construímos nosso plano de ação pedagógica com foco na inclusão do estudante do PARFOR na pesquisa enquanto prática de conhecimento e intervenção. Nossa discussão preliminar busca também na experiência de diálogos interdisciplinares durante as aulas, respostas para mudanças de concepção de ensino e aprendizagem nos cursos de Formação Inicial de Professores da Educação Básica, por se entender que esta experiência favorece o diálogo interdisciplinar a partir do momento em que docentes e estudantes reconhecem a inter-relação dos saberes em seu processo de formação.

$O$ diálogo interdisciplinar favorece uma aprendizagem significativa e dá ênfase à postura reflexiva, ao possibilitar o pensamento crítico e, sobretudo, a dinamicidade no processo de ensino e a apropriação do conhecimento, sendo, portanto, concebido como ação intencionalmente pensada para articular teoria e prática de forma viva numa linha pedagógica que privilegia o diálogo e a problematização no processo de articulação entre múltiplos saberes.

Nessa perspectiva, entende-se que a ação docente para atribuir sentido ao processo de construção de conhecimentos na perspectiva interdisciplinar, precisa nortear-se por um currículo que reconheça e respeite o direito do outro à diversidade, que promova desafios na formação de identidades flexíveis e valorize a pluralidade cultural, estimulando a vivência de princípios pedagógicos que coloquem o processo de formação no patamar de instrumento promotor de uma “educação que prioriza a cidadania, a cultura da paz, a ética nas relações interpessoais, e principalmente o incentivo ao espírito crítico quanto às desigualdades sociais e culturais presentes seja no cotidiano educacional ou social" (TEBAR,2011, p.25).

Nesse caso, não lhe cabe desqualificar ou ignorar as experiências dos estudantes e sim tentar incorporá-las, a fim de que eles percebam uma articulação da vida social com seu cotidiano. E ao estimular a liberdade de expressão deve encorajá-los a atuar criticamente em outras instâncias do mundo social. Ensinando-os, mas, principalmente, 
vivenciando com eles, de forma aberta, as diversas manifestações culturais, impregnadas de crenças, costumes e valores pertinentes a cada sujeito, e que devem ser respeitados em função da sua história de vida. É preciso que o educador reconheça que a humanidade caracteriza-se pela produção da linguagem como sistema simbólico, que torna possível a construção de referenciais culturais, o desenvolvimento cognitivo, a formação e circulação de valores.

A prática docente ao ser pautada por uma metodologia interdisciplinar viabiliza um diálogo entre componentes curriculares, sem, entretanto, nenhum componente perder a essência da especificidade de seus conteúdos. Promove a interação interna entre saberes a partir do estabelecimento de parcerias entre seus pares para se chegar a um objetivo comum. Pois, a interdisciplinaridade abre espaços para diálogos com temas diversificados, dentre estes, inclusão da cultura Afro e Indígena no currículo escolar; interculturalidade e multiculturalidade no meio social. Assim, a multiplicidade de saberes da sala de aula abre espaços para o diálogo entre os saberes, sejam eles da vida cotidiana ou oriundos da ciência.

Essa discussão é uma necessidade emergente da escola pública atual, pois o diálogo entre saberes no contexto de sala de aula apresenta momentos interdisciplinarmente entrelaçados, ou seja, a investigação temática pela qual aluno e professor buscam no universo vocabular da sociedade onde vivem as palavras e temas centrais de sua biografia; $a$ tematização pela qual eles codificam e decodificam esses temas; ambos buscam o seu significado social, tomando assim consciência do mundo vivido; a problematização na qual eles buscam superar uma primeira visão mágica por uma visão crítica, partindo para a transformação do contexto vivido, constituindo-se dessa forma como sujeito. Porém não basta ser sujeito de um projeto monocultural, pois sabemos que essa perspectiva leva a um ensino fragmentado à luz de uma construção isolada do conhecimento.

Sabemos ainda que o respeito à diversidade tem em si a perspectiva ética e, nesse caso, ao se abordar a pluralidade cultural do Brasil na sala de aula, o professor ensina ao estudante a ter sentimento de valorização cultural pelo país, além do reconhecimento e respeito às diferentes culturas, mostrando que não existe uma melhor ou mais desenvolvida que a outra. 
Por esse viés, há necessidade de que nos cursos de formação de professores, sejam explorados atividades interdisciplinares que levem o professor a conhecer estratégias de ensino que despertem no estudante para a curiosidade, para a relação de pertencimento com a cultura de seu país e para o entendimento sobre a importância e o valor da raiz histórica da cultura afro e indígena na história do Brasil. Portanto, a atividade interdisciplinar favorece o estudo da diversidade por vários ângulos, pois pode ser compreendida como sendo a troca de reciprocidade

\section{Metodologia}

Nossa pesquisa ocorreu durante as aulas das disciplinas Educação e Multiculturalismo, e Ética e Cidadania no Curso de Licenciatura em Pedagogia da Universidade de Pernambuco localizada no município de Garanhuns no interior do Estado, envolvendo cento e vinte (120) estudantes, sendo sessenta (60) estudantes de uma turma de $1^{\circ}$ período e sessenta (60) estudantes de uma turma de $3^{\circ}$ período; dois (02) coordenadores pedagógicos, três (03) professores, (02) duas lideranças indígenas e treze (13) estudantes indígenas Fulni-ô do município de Águas Belas, perfazendo um total de cento e quarenta (140) participantes da pesquisa.

Os procedimentos da pesquisa foram: rodas de diálogos e mesa redonda com a participação dos indígenas para questionamentos acerca da cultura desse povo e as implicações no processo de ensino e de aprendizagem. Utilizamos como indicadores de resultados: pesquisa bibliográfica; compreensão, interpretação, análise e pesquisas em grupo, para o desenvolvimento da parte teórica e para a pesquisa de campo, entrevistas com representantes das diversas instâncias sociais envolvidas direta ou indiretamente com a cultura indígena; e, apresentação de questionamentos sobre a diversidade cultural e a forma com os cursos de formação docente estão trabalhando a temática da diversidade cultural na escola pública.

\section{Análise e discussão dos resultados}


Com a intenção de promover estudos e pesquisa, oportunizando ao estudante estabelecer relações entre os conteúdos e temas de diversos componentes presentes na Matriz Curricular do $1^{\circ}$ e $3^{\circ}$ períodos do Curso de Pedagogia no PARFOR, estabelecemos um link com as disciplinas de Educação e Multiculturalismo e Ética e Educação, as quais se articulam entre si a partir da dimensão histórica, social e política. Nesse sentido, delineamos nosso estudo através de uma atividade de pesquisa que busca inserir os estudantes enquanto pesquisadores a partir de sua ação docente no cotidiano das Escolas de Educação Básica.

A proposta de trabalho norteou o estudo com abordagens teóricas e ações pedagógicas voltadas para a pesquisa enquanto intervenção nos entraves de ensino e aprendizagem, tão presentes nas discussões dos estudantes que ocupam os bancos universitários do PARFOR, ao direcionar o olhar para seu fazer educacional.

Em Educação e Multiculturalismo e na disciplina Ética e Educação propomos aos estudantes leituras de textos abordados por Candau (2002, p. 87-90), Lei No 11645, PCNs (2001, p. 7-9), LDBEN (1996) e em rodas de diálogos solicitamos que registrassem os pontos mais significativos e relevantes contidos nos textos estudados e discutidos. Partindo desse delineamento, os estudantes foram orientados a relacionar os conhecimentos construídos com as características e desafios dos sistemas produtivos vivenciados nos seus espaços de atividade docente conforme cada realidade vivida. Apesar das limitações apresentadas inicialmente na prática da produção de leitura, escrita e interpretação textual, conseguiram realizar, individualmente, uma síntese crítica sobre Multiculturalismo, Ética e Educação, contemplando também os conceitos e as discussões abordadas nas rodas de diálogos com a realidade local das escolas de atuação dos estudantes pesquisadores.

Objetivamos com essa atividade, estudar os conceitos e conteúdos dessas disciplinas contempladas no PARFOR, articulando-os com as temáticas e conceitos novos abordados na roda de diálogo e com a realidade local (de cada escola pesquisada pelo estudante).

Partindo desse direcionamento, os estudantes elaboraram textos e situações didáticas envolvendo o Multiculturalismo e Ética na 
perspectiva de intervenção junto as escolas campo de trabalho desses estudantes-pesquisadores. Delinearam, através de rodas de diálogos, várias reflexões sobre as experiências de integração de saberes à luz da discussão sobre como as aprendizagens construídas se relacionam e contribuem na compreensão e intervenção crítica de cada realidade apresentada. Como desafio, sugerimos a elaboração de um Diário de Bordo, em que os estudantes-pesquisadores registraram num caderno e/ou classificador suas construções, dúvidas, evidências, descobertas, desafios e aspectos que consideraram mais significativos em relação aos conteúdos estudados e discutidos.

Vários questionamentos começavam a emergir dos estudantespesquisadores, dentre eles, "como faremos uma comparação entre os conceitos e teorias estudadas se estamos com tantas atividades nas escolas em que lecionamos? Não temos tempo para realizar pesquisa em escola. Mal temos tempo para assistir aulas no" PARFOR. "Como vamos dar conta de tantos estudos e atividades" definidas nessas disciplinas?

Diante dessas inquietações, realizamos algumas rodas de diálogos entre os estudantes, sensibilizando-os a entender como se faz relevante a prática da pesquisa, da comunicação de ideias e da socialização de produções às mudanças que definimos como satisfatórias no cenário educacional em termos de ensino e aprendizagem.

Esses momentos nos permitiram perceber que os questionamentos eram oriundos da dificuldade desses estudantes com o estudo teórico aprofundado e com a pouca familiarização que possuem em relação à pesquisa. Retomamos ao foco inicial "Diversidade Cultural e Diálogos Interdisciplinares" e mostramos aos estudantes-pesquisadores a necessidade da troca de experiências e da oportunidade de estudar teorias necessárias ao aperfeiçoamento e melhoria dos conhecimentos científicos necessários ao sucesso de sua prática pedagógica.

Os estudantes entenderam a relevância do diálogo interdisciplinar para a qualidade de sua formação e, enquanto pesquisadores, se motivaram para o estudo individual e em grupos, elaboraram planos de pesquisas visando a aplicação de atividades significativas sobre multiculturalismo e ética nos espaços escolares. Além disso, produziram questões abertas e fechadas sobre Ética e 
Multiculturalismo visando conhecer a opinião de estudantes dos anos iniciais do Ensino Fundamental das escolas em que atuam como professores.

Os resultados coletados foram estudados e analisados a partir do método de comparação e levantamento. Processo em que as respostas dos entrevistados foram tabuladas e, a partir desse resultado, realizaram pesquisas em livros, artigos e/ou revistas com depoimentos de pelo menos dois autores estudados durante as aulas, o que gerou a elaboraram de slides e a produção de textos construídos através das discussões, inferências e socializações de conhecimentos em intercâmbios com outros estudantes, durante as aulas presenciais e nas aulas de pesquisa.

Nesse contexto, os estudantes foram oportunizados ainda a apresentar em mesa redonda o resultado da pesquisa, e socializaram essas produções em espaços de interlocuções bastante produtivos e inovador. Como resultado, extraímos vários depoimentos dos estudantes, dentre eles, a reflexão de alguns que esse foi o primeiro momento de exposição e interlocução realizado junto a profissionais de educação; bem como de leitura e interpretação textual para produção de novos textos oriundos da criticidade e do estudo enquanto produtores de cultura e conhecimentos.

No momento de culminância dessas produções, reunimos estudantes de todas as turmas dos Cursos de Licenciatura em Pedagogia da Plataforma Freire e, convidamos professores, coordenadores, lideranças (representantes do Cacique e Pajé) e estudantes de escolas Indígenas Fulni-ô, localizadas no Aldeamento Fulni-ô no município de Águas Belas em Pernambuco, para ministrar palestras e participar de mesas redondas sobre a história e cultura indígena, onde os estudantespesquisadores através de rodas de diálogos interagiram com a história dessa etnia. Essa prática estimulou o debate multicultural e contribuiu de forma significativa para que conhecessem na prática, os conceitos de Multiculturalismo e de Ética na Educação na perspectiva da diversidade estudada nos espaços de formação. Perceberam também, os avanços, as dificuldades e as proposições da sociedade atual para as questões multiculturais. E, em seguida, os estudantes apresentaram relatos das experiências vivenciadas nos espaços de atuação docente, sendo oportunizados a relacionar os conhecimentos construídos com as 
características e desafios propostos pela dimensão de currículo multicultural visando à melhoria de sua prática pedagógica nas etapas da Educação Básica em que se inserem enquanto docentes e estudantes-pesquisadores.

Nos estudos realizados pudemos perceber que ainda existe pouco conhecimento do professor de Educação Básica, em conhecer e trabalhar com a diversidade cultural na perspectiva de um trabalho que "promova uma atitude de visualização de todos os grupos étnicoculturais como portadores de cultura" (CANEN, 2001, p.213) nos espaços de sala de aula, sobretudo nos anos iniciais do Ensino Fundamental. Acrescenta-se a isso, que as concepções que ainda se fazem presentes nas escolas públicas de nosso país, têm apresentado pouca contribuição em estudos que valorizem a cultura dos grupos étnicos, especialmente a cultura indígena. Os resultados da pesquisa realizada e da mesa de discussão com os povos indígenas, revelou essa realidade e também que a forma como os docentes têm tratado essas questões seja em sala de aula, seja através de pesquisas, ainda é bastante limitada. Sabemos que durante muito tempo,

os estudos multiculturais ou pesquisas multiculturais em currículo e formação docente, seriam consideradas aqueles que questionassem mecanismos que silenciam e/ou interditam identidades com base em determinantes de gênero, etnia, classe social, raça, "deficiência" física ou mental, padrões linguísticos e culturais assim por diante (CANEN, ARBACHE e FRANCO, 2001, p. 166).

Partindo dessa constatação, há necessidade de que os futuros docentes interajam com as categorias centrais das práticas multiculturais tanto na instituição formativa como no lócus da Educação Básica como professores da rede municipal e estadual e/ou nos estágios para conclusão do curso de Licenciatura em Pedagogia, como meio de se apropriar de conhecimentos sólidos que os auxiliem na elaboração de projetos e de ações multiculturalmente orientadas.

Enfim, os resultados da pesquisa e dos estudos desenvolvidos comprovaram que ainda há muito a se fazer para inserir o currículo da Educação Superior no contexto da Diversidade Cultural e de diálogos interdisciplinares com a Educação Básica, uma vez que a prática docente precisa ser conduzida de forma articulada às práticas multiculturais. Portanto, o estudo interdisciplinar que envolveu as 
disciplinas Educação e Multiculturalismo e Ética e Cidadania abre espaços para o fortalecimento da inclusão social e para o diálogo inter e multicultural, uma vez que são ações dessa natureza que asseguram uma relação dialógica e transformadora no campo da formação inicial de professores da Educação Básica. Canen \& Oliveira (2002, p. 89),

\begin{abstract}
sugerem três categorias centrais ao se pensar em práticas pedagógicas multiculturais. Essas categorias são a crítica cultural, que deve estar presente nos discursos e consiste na possibilidade dada aos alunos para analisar suas identidades e criticar mitos sociais que os subjugam: a hibridização discursiva, que busca ressignificar o discurso pedagógico possibilitando a construção de uma linguagem híbrida, cruzando fronteiras culturais, incorporando discursos múltiplos, reconhecendo a pluralidade e provisoriedade de tais discursos; e a ancoragem social dos discursos, onde se fazem conexões entre os discursos históricos, políticos, sociológicos, culturais e outros, buscando entender como dado conceito surgiu historicamente e passou a ser erroneamente visto como universal.
\end{abstract}

Sob o olhar dessa proposição, desenvolvemos a presente pesquisa e os resultados confirmaram que o trabalho com a sensibilização multicultural nos campos do currículo e da formação docente, é relevante, sobretudo, para preparar professores e estudantes nos valores da tolerância e a apreciação da diversidade cultural, uma vez que por essa sensibilização há ricas possibilidades de mudanças qualitativas na práxis educativa.

\title{
Considerações finais
}

A discussão e análise dos resultados da pesquisa desenvolvida por estudantes do Curso de Pedagogia do PARFOR no Campus da UPE/Garanhuns e representantes das escolas indígenas Fulni-ô localizadas no município de Águas Belas, nos remetem a compreensão de que estudos acerca da Diversidade Cultural na escola pública têm sido considerados nos dias atuais, uma necessidade básica para o exercício da cidadania. As pesquisas comprovam também que, é possível promover mudanças de atitudes e novas concepções sobre 
diversidade cultural, partindo de metodologias que fortaleçam os diálogos interdisciplinares no currículo escolar da Educação Básica. Revelam ainda que o olhar nessa direção deve começar pelos Cursos de formação inicial de professores, uma vez que estes vão atuar na escola de Educação Básica, sobretudo nos anos iniciais do Ensino Fundamental. Para tanto, é necessário que o olhar dos professorespesquisadores se voltem para o Currículo na dimensão dinâmicodialógica em seu processo de estudo e ensino, articulando teoria e prática enquanto diálogo interdisciplinar como forma de incentivar o estudo da diversidade cultural na e para a ação docente.

Justifica-se essa hipótese na constatação de que, por meio de estudos e pesquisas sobre diversidade cultural e interdisciplinaridade, o estudante - pesquisador comunica suas idéias e articula o conhecimento unindo a base teórica apreendida nos espaços de formação ao conhecimento contextualizado.

Sendo assim, enquanto professores e pesquisadores, verificamos a necessidade de que se desenvolvam projetos de extensão que priorizem a valorização da cultura indígena e do respeito a diversidade cultural e a interculturalidade no currículo da formação inicial de professores, como meio de qualificação profissional e de reflexos positivos no fazer docente da Educação Básica a partir de um olhar direcionado para a inclusão social.

A importância desse trabalho está relacionada, portanto, à possibilidade de produzir informações que contribuam para promover a valorização, o diálogo e o respeito à diversidade cultural na formação inicial dos docentes. A relevância se torna ainda maior se levarmos em conta que "as oportunidades formais de educação continuada não são as mesmas para todos os professores do país e por isso, a formação inicial deveria tender à excelência" (GONÇALVES e GONÇALVES, 1998, p.107).

\section{Referências}

BRASIL. Lei de Diretrizes e Bases Educação Nacional. Lei n. 9394/96. Brasília, MEC, 1996. 
Secretaria de Educação Fundamental. Parâmetros Curriculares Nacionais. $\mathbf{1}^{\mathrm{a}}$ a $\mathbf{4}^{\mathrm{a}}$ séries. Introdução. Brasília: MEC/SEF, v. 1, 2001.

. Lei no 11.645 de 10 de março de 2008. Disponível em: http://www.planalto.gov.br/ccivil_03/_Ato20072010/2008/Lei/L11645.htm

CANDAU, V. M.(org.) Sociedade, educação e cultura(s): questões e propostas. Petrópolis, RJ: Vozes, 2002.

CANEN, A. A Pesquisa Multicultural como Eixo na Formação Docente: potenciais para a discussão da diversidade e das diferenças. Ensaio. Avaliação e Políticas Públicas e Educação. 2001.

CANEN, A.; ARBACHE, A. P.; FRANCO, M. Pesquisando Multiculturalismo e Educação: o que dizem as dissertações e teses. Educação e Realidade, Porto Alegre- RS, v. 26, n. 1, 2001. p. 161-181.

CANEN, A. \& OLIVEIRA, A.M.A.(2002). Multiculturalismo e Currículo em Ação: um estudo de caso. Revista Brasileira de Educação, n.21, p.61-74.

GONÇALVES, T. V. e GONÇALVES, T. O. Reflexões sobre uma prática docente situada: buscando novas perspectivas para a formação de professores. In: GERALDI, C. M. G.; FIORENTINI, D.; PEREIRA, E. M. A. (Orgs.) Cartografia do Trabalho Docente: professor (a) pesquisador (a). Mercado das Letras: Campinas, SP, 1998.

NÓVOA, A. Os professores e as histórias da sua vida. In: Novo, A. Vidas de Professores. Ed. Porto, 1995.

TEBAR, Lourenzo. O perfil do professor mediador: pedagogia da mediação. Tradução de Priscila Pereira Mota. São Paulo, SENAC, 2011. 